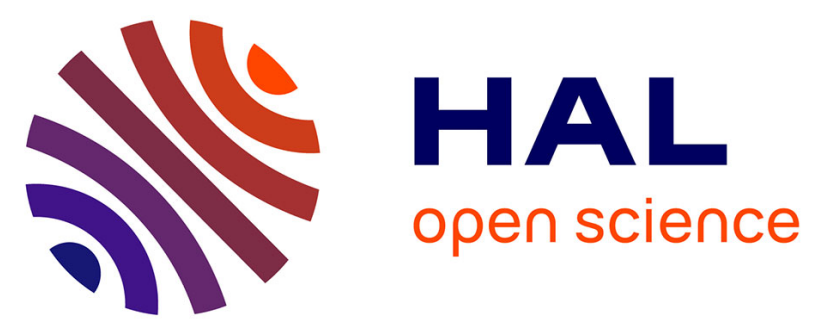

\title{
COMPARISON OF THE POROSITY OF SCAFFOLDS MANUFACTURED BY TWO ADDITIVE MANUFACTURING TECHNOLOGIES: SLA AND FDM
}

Bernardo Vieira Magaldi, Marianna de Oliveira da Costa, Rossana Mara da Silva Thiré, Anna Carla Araujo

\section{To cite this version:}

Bernardo Vieira Magaldi, Marianna de Oliveira da Costa, Rossana Mara da Silva Thiré, Anna Carla Araujo. COMPARISON OF THE POROSITY OF SCAFFOLDS MANUFACTURED BY TWO ADDITIVE MANUFACTURING TECHNOLOGIES: SLA AND FDM. 24th International Congress of Mechanical Engineering, 2018, Curitiba, Brazil. hal-03226784

\section{HAL Id: hal-03226784 \\ https://hal.science/hal-03226784}

Submitted on 15 May 2021

HAL is a multi-disciplinary open access archive for the deposit and dissemination of scientific research documents, whether they are published or not. The documents may come from teaching and research institutions in France or abroad, or from public or private research centers.
L'archive ouverte pluridisciplinaire HAL, est destinée au dépôt et à la diffusion de documents scientifiques de niveau recherche, publiés ou non, émanant des établissements d'enseignement et de recherche français ou étrangers, des laboratoires publics ou privés. 


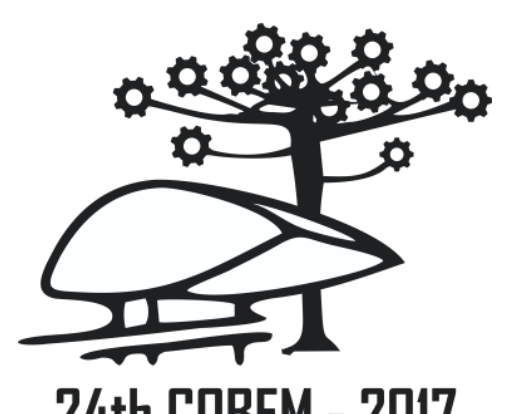

\section{DABEM}

24th $A B C M$ International Congress of Mechanical Engineering December 3-8, 2017, Curitiba, PR, Brazil

\section{4th CDBEM - 2017}

\section{COBEM-2017-1460 \\ COMPARISON OF THE POROSITY OF SCAFFOLDS MANUFACTURED BY TWO ADDITIVE MANUFACTURING TECHNOLOGIES: SLA AND FDM}

Bernardo Vieira Magaldi

Universidade Federal do Rio de Janeiro, POLI/COPPE, Program of Metallurgical and Materials Engineering, Rio de Janeiro, RJ, Brazil

Universidade Federal do Rio de Janeiro, POLI/COPPE, Programa of Mechanical Engineering, Rio de Janeiro, RJ, Brazil

bernardomagaldi@poli.ufrj.br

\section{Marianna de Oliveira da Costa Maia Pinto}

Universidade Federal do Rio de Janeiro, POLI/COPPE, Program of Metallurgical and Materials Engineering, Rio de Janeiro, RJ, Brazil

mocosta@metalmat.ufrj.br

Rossana Mara da Silva Moreira Thiré

Universidade Federal do Rio de Janeiro, POLI/COPPE, Program of Metallurgical and Materials Engineering, Rio de Janeiro, RJ, Brazil

rossana@metalmat.ufrj.br

\section{Anna Carla Monteiro de Araújo}

Universidade Federal do Rio de Janeiro, POLI/COPPE, Programa of Mechanical Engineering, Rio de Janeiro, RJ, Brazil anna@mecanica.ufrj.br

Abstract. Scaffolds are 3D-porous biomaterials used for tissue engineering. Their physical, chemical and biological properties are strongly dependent upon the fabrication process. Additive Manufacturing (AM) is a fabrication process for serial production of complex structures designed by virtual models and based on the addition of layers. Fused Deposition Modeling (FDM) produces each layer by heating-extrusion of polymer/composite filament. The raw material used in Stereolithography (SLA) is a liquid resin that is transformed to the solid state by the photopolymerization process. The objective of this work is to evaluate the structure of the scaffolds produced by the two processes: FDM and SLA. Different geometry configurations are manufactured and the volumes of workpieces are compared as quality integrity of the specimens. In spite of using different polymers for each AM process, it was observed that FDM parts presented higher porosity and lower dimensional deviation in relation to digital model than SLA parts for all geometries. However, the quality of deposited filaments was higher for SLA scaffolds.

Keywords: Additive Manufacturing, SLA, FDM, Scaffolds, Porosity

\section{INTRODUCTION}

Additive Manufacturing (AM) is a process of manufacturing parts from the construction of layers to constitute the geometry originated from a digital geometric model. The ability to fabricate parts of complex geometry is an advantage of using additive manufacturing (Galeta et al., 2016). 3D printing techniques have been employed in Tissue Engineering to produce porous scaffolds with complex geometries and controllable porosity (Giannitelli et al., 2014). Pore geometry, pore interconnectivity and mechanical properties are physical parameters, which define a scaffold's performance.

The digital model created in the computer-aided system (CAD) is converted into a simpler digital file structure that contains only information related to body volume contours (STL). From the STL file it is possible to discretize the volume in layers with constant thickness so that the equipment can produce each layer to be printed (Bose et al., 2013).

Currently there are different AM techniques with high precision and a range of materials available in the market, divided into three groups: liquid based, solid based and powder based. Stereolithography (SLA), Fused Deposition Modeling (FDM) and Selective Laser Sintering (SLS) stand out in each of these groups, respectively. 
SLA commonly uses monomers, but can also be made with hydrogels or with ceramic compounds. Fabrication by SLA is carried out from the photopolymerization of the liquid resin, which can be epoxy or acrylic. When ultraviolet (UV) or laser light is applied, the resin passes from the liquid state to the solid, a process that repeats layer by layer for the total construction of the part. Among its limitations, the most critical in the SLA process are the contraction and the marginal discrepancy of the influence on the reproducibility of the parts (Kim et al., 2017). The photopolymerization of a new layer is closely linked to the previous one, which produces a minimal anisotropy and homogeneous properties of the printed parts (Alharbi et al., 2016).

FDM constructs parts usually from thermoplastic polymer filaments. The raw material is heated by a print head which is moved through guides whose movement is performed by programming numerical control (Bose et al., 2013). It is a relatively inexpensive technique compared to other additive manufacturing techniques and does not require the use of solvents for the post-processing of the material. The use of the filament-shaped material allows for continuous production, not requiring the replacement of the raw material. In FDM technology, the study of the uniformity of printed pieces is also interesting, because depending on the pattern of filling of the solid, the properties of the piece produced vary.

In this work, the parts quality and morphological properties of the same set of mechanical elements manufactured by the two techniques: SLA and FDM are evaluated. The designed elements are structures with different pattern filling orientations and, consequently, generating different cavities and degrees of porosity.

\section{EXPERIMENTAL PROCEDURE}

The same geometry will be used to fabricate elements in the two AM techniques. This geometry was initially designed to be manufactured by FDM, so it was chosen to work with filament geometry. Four similar computational models were designed initially with different orientations for the FDM manufacture: $0^{\circ}-90^{\circ} ; 0^{\circ}-45^{\circ}-90^{\circ} ; 0^{\circ}-60^{\circ}-120^{\circ}$ and $0^{\circ}-45^{\circ}-90^{\circ}-135^{\circ}$, represented in Fig. 1 A to D, respectively, with dimensions of $5 \mathrm{~mm} \times 5 \mathrm{~mm}$ of side, with different heights: $1.8 \mathrm{~mm}$ for the first three and $2.4 \mathrm{~mm}$ to the fourth. The models were transformed in STL files for manufacturing.
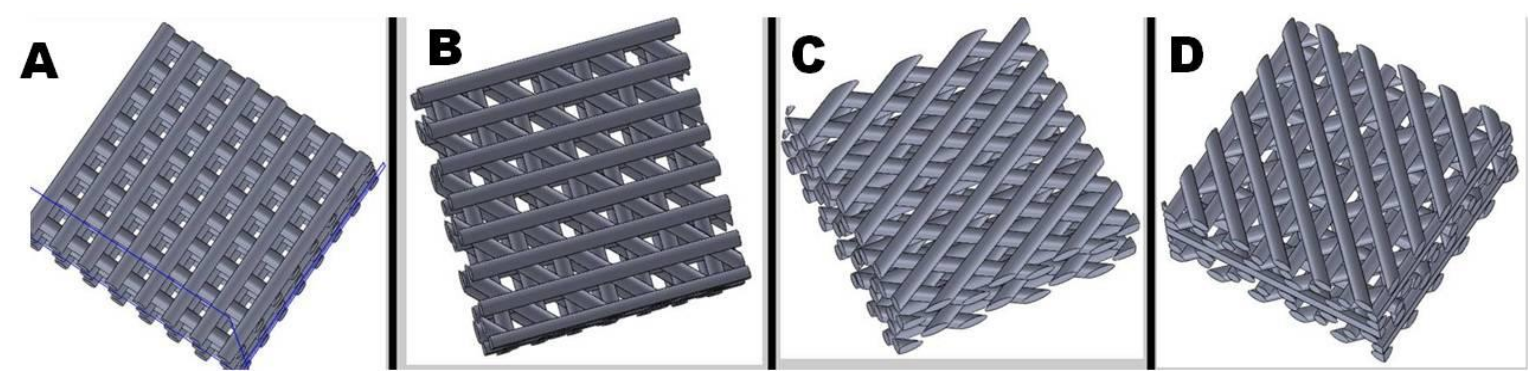

Figure 1. CAD models with different geometries: (A) $0^{\circ}-90^{\circ}$; (B) $0^{\circ}-45^{\circ}-90^{\circ}$; (C) $0^{\circ}-60^{\circ}-120^{\circ}$ and (D) $0^{\circ}-45^{\circ}-90^{\circ}-$ $135^{\circ}$

The fused deposition modeling (FDM) used was 3D Cloner (Microbrás®, Brazil). The parts were printed with the print head extrusion temperature set at $220^{\circ} \mathrm{C}$, layer thickness of $0.3 \mathrm{~mm}$ and resolution of $0.050 \mathrm{~mm}$. The material used as a feedstock in the FDM technique was poly(lactic acid) (PLA), commercially obtained as white filament of $1.75 \mathrm{~mm}$ diameter manufactured by eSun (China), purchased from the company Commercial Sazobras Ltda. The designs were made with struts of $0.30 \mathrm{~mm}$ in diameter and distance between struts of $0.68 \mathrm{~mm}$. Figure 2 shows the three-dimensional model of the path traveled by the print head during fabrication process of the parts by FDM.

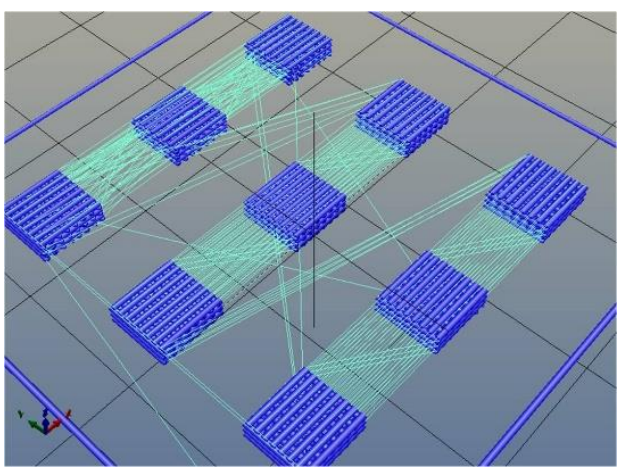

Figure 2. Three-dimensional model of the path traveled by the print head in FDM 
SLA equipment used was the Projet 1200 manufactured by 3D Systems®. The longitudinal plane resolution is 0.056 $\mathrm{mm}$ and the layer thickness is $0.03 \mathrm{~mm}$. The photopolymerizable resin used for the production of the parts was VisiJet FTX Green [Triethylene glycol diacrylate, and dimethanol diacrylate of tricyclodecane] having as a photoinitiator the phenyl oxide bis (2,4,6-trimethylbenzoyl) phosphine supplied by 3D Systems ${ }^{\circledR}$.

To be produced in the SLA printer, the pieces were placed on square base blocks of $7 \mathrm{~mm}$ side and $3 \mathrm{~mm}$ high (Fig. 3 ), to improve the adherence between the printed parts and the build platform when done without this support base.

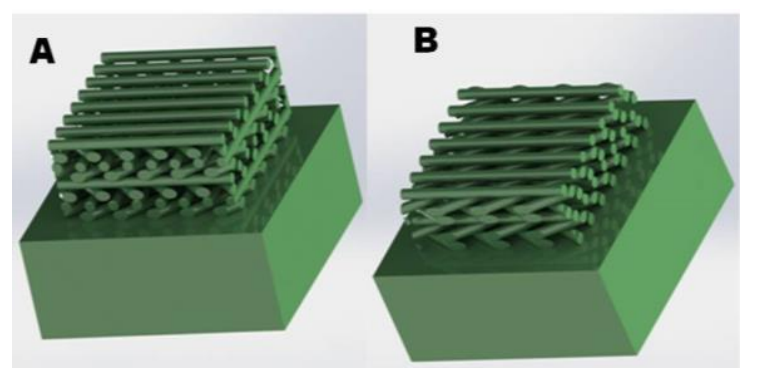

Figure 3. CAD models with square base for SLA printing: a) $0^{\circ}-45^{\circ}-90^{\circ}-135^{\circ}$ and b) $0^{\circ}-60^{\circ}-120^{\circ}$

In SLA technique, four series of the four models were made, so as not to repeat the same position at build platform. The manufacturing time for each series was 29 minutes. As post-processing, solvent (isopropyl alcohol) was applied to remove the excess of polymer resin, and low-pressure air blasting for better removal of the uncured mixture from the pores. Subsequently, a support was placed with the parts in the post-process chamber of the machine, for about 24 minutes for each series. Then, the pieces were sanded with their bases granulation 3M® paper 220 sandpaper, to remove the parts, being blasted with low-pressure air to remove possible after grinding from the bases. The scaffolds obtained were measured with a caliper.

For the morphological evaluation of the pieces produced by both techniques, scanning electron microscopy (SEM) was used (Tabletop Microscope TM3030). The samples were covered with a thin layer of gold to avoid electric loading and the micrographs were obtained using an acceleration voltage of $15 \mathrm{kV}$. The dimensional error $(\Delta \mathrm{d} \%)$ of the parts made by SLA and FDM related to the designed ones are measured. For the porosity calculation Archimedes principle was used to calculated density of the parts, according to ASTM F2450 - 10 - "Standard Guide for Assessing Microstructure of Polymeric Scaffolds for Use in Tissue Engineered Medical Products". To determine the density $\rho$, the dry mass and the apparent mass of the pieces were measured with a hydrostatic balance in ethanol, according to Eq. (1). The density of ethanol $\rho_{\mathrm{e}}$ is $0.79 \mathrm{~g} / \mathrm{cm}^{3}$.

$$
\rho=\frac{W_{d r y} \times \rho_{e}}{\left(W_{d r y}-W_{w e t}\right)}
$$

Where the dry mass is $\mathrm{W}_{\text {dry }}$ and wet mass is $\mathrm{W}_{\text {wet }}$ when immersed in ethanol. The pore volume $\left(\mathrm{V}_{\mathrm{p}}\right)$ on the printed parts is obtained by the Eq. (2) considering the apparent volume $\left(\mathrm{V}_{\mathrm{a}}\right)$ calculated using the external dimensions of the model:

$$
V_{p}=V_{a}-\frac{W_{d r y}}{\rho}
$$

The porosity p was calculated by Equation (3):

$$
p(\%)=\frac{V_{p}}{V_{a}} \times 100 \%
$$

The theoretical porosity $\left(\mathrm{p}_{\mathrm{t}}\right)$ of each model can be obtained using the geometrical model and considering as real the theoretical volume of scaffolds $V_{t}$, given by the Solidworks ${ }^{\circledR}$ software. Eq. 4 gives the predicted porosity.

$$
p_{t}(\%)=\frac{V_{a}-V_{t}}{V_{a}} \times 100 \%
$$




\section{RESULTS AND DISCUSSION}

Figures 4 and 5 showed SEM images of scaffolds produced by FDM and SLA processes with different layer orientations, respectively. It can be observed that the scaffolds obtained by FDM (Fig. 4) were less homogeneous than those obtained by SLA (Fig. 5), with respect to the deposition of each printed layer.

This fact may be related to the presence of non-projected filaments derived from the process for the production of the parts, when a little polymer material is extruded during the trajectory followed by the FDM print head (Fig. 2). Also due to the extrusion process and the speed of displacement of the print head, there is a variation of the thickness across the filaments.

From the SEM images (Figure 5) it can be seen that the cylindrical sections of the $0^{\circ}-45^{\circ}-90^{\circ}-135^{\circ}$ scaffolds were not homogeneous, varying their thicknesses along their length. The section variation of the filament may be the product of a number of factors, such as beam intensity and its distribution in each pixel. Artifacts are also observed (circulated in Fig. 5B), possibly related to polymer residues that were not removed in the application of isopropyl alcohol and therefore were cured in the post-cure.
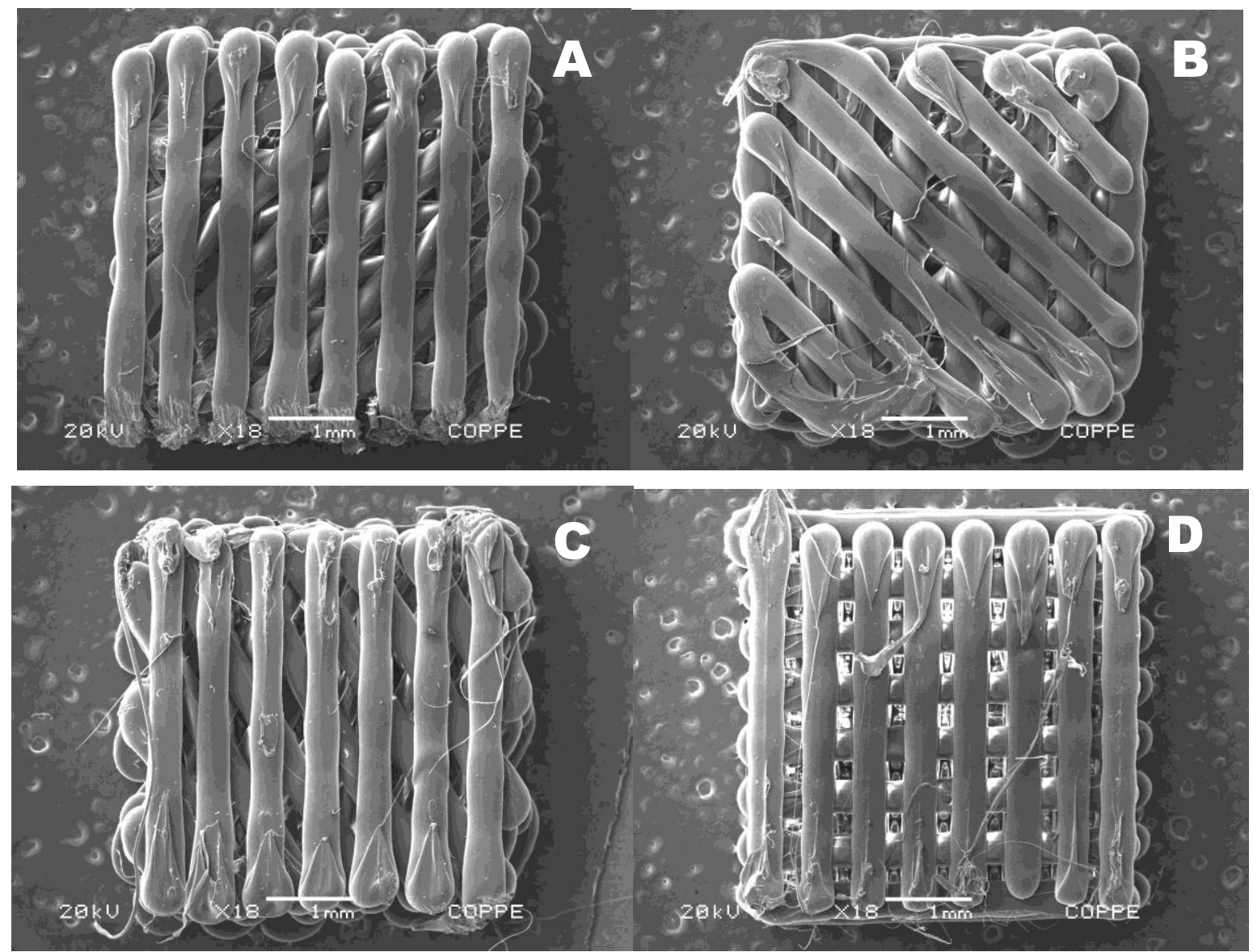

Figure 4. SEM images of scaffolds produced by FDM with different geometries: (A) $0^{\circ}-45^{\circ}-90^{\circ}$; (B) $0^{\circ}-45^{\circ}-90^{\circ}-135^{\circ}$; (C) $0^{\circ}-60^{\circ}-120^{\circ}$ and (D) $0^{\circ}-90^{\circ}$ 


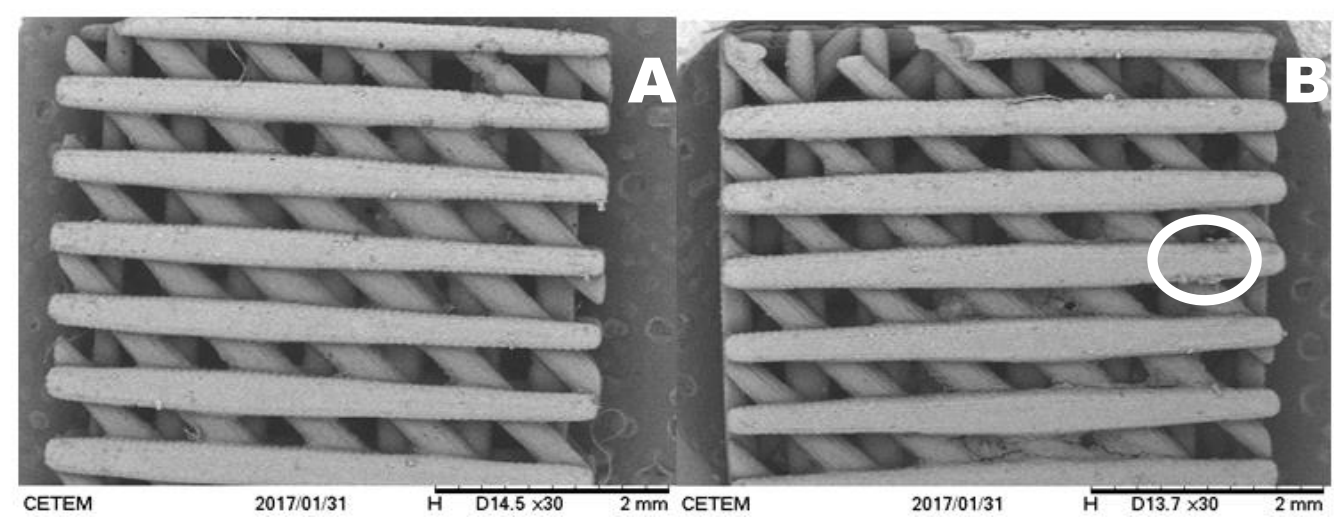

Figure 5. SEM images of scaffolds produced by SLA with different geometries: (A) $0^{\circ}-45^{\circ}-90^{\circ}$, (B) $0^{\circ}-45^{\circ}-90^{\circ}-135^{\circ}$

The sanding process to remove the bases from SLA scaffold did not remove part of the base, or it ended up removing in excess which resulted in a much larger dimension error in the Height (z), as is shown in Table 2, where it can also compare Table 1, showing that despite the sanding, the parts made by SLA was much more faithful to the original dimensions than by the FDM technique.

Table 1. Dimensional Errors (\%) in the pieces produced by FDM in relation to the CAD model.

\begin{tabular}{|c|c|c|c|c|}
\hline Dimensions / Geometries & $0^{\circ}-90^{\circ}$ & $0^{\circ}-45^{\circ}-90^{\circ}$ & $0^{\circ}-45^{\circ}-90^{\circ}-135^{\circ}$ & $0^{\circ}-60^{\circ}-120^{\circ}$ \\
\hline Height (z) (\%) & $-8,3$ & $-10,6$ & 3,5 & 12,2 \\
\hline Length (y) (\%) & 8,6 & 0,8 & $-3,2$ & $-7,2$ \\
\hline Width (x) (\%) & 7,0 & 2,0 & $-4,0$ & $-3,2$ \\
\hline
\end{tabular}

Table 2. Dimensional errors of the parts produced by SLA.

\begin{tabular}{|c|c|c|c|c|}
\hline Dimensions / Geometries & $0^{\circ}-90^{\circ}$ & $0^{\circ}-45^{\circ}-90^{\circ}$ & $0^{\circ}-45^{\circ}-90^{\circ}-135^{\circ}$ & $0^{\circ}-60^{\circ}-120^{\circ}$ \\
\hline Height (z) (\%) & $-10,6$ & 20,0 & 0,4 & 6,7 \\
\hline Length (y) (\%) & $-1,2$ & $-3,4$ & $-3,0$ & $-4,6$ \\
\hline Width (x) (\%) & $-1,4$ & $-3,4$ & $-2,6$ & $-2,2$ \\
\hline
\end{tabular}

To evaluate the porosity of the parts of both techniques were calculated densities as shown in Tables 3 and 4. According to Equation (1) of the calculation of the porosity by Archimedes principle in the norm ASTM F2450.

Table 3. Density of the parts manufactured by SLA.

\begin{tabular}{|c|c|c|c|c|}
\hline Measurements / Geometries & $0^{\circ}-90^{\circ}$ & $0^{\circ}-45^{\circ}-90^{\circ}$ & $0^{\circ}-45^{\circ}-90^{\circ}-135^{\circ}$ & $0^{\circ}-60^{\circ}-120^{\circ}$ \\
\hline Dry mass (g) & $0,0266 \pm 0,0046$ & $0,0355 \pm 0,0103$ & $0,0414 \pm 0,0101$ & $0,0328 \pm 0,0211$ \\
\hline Wet mass (g) & $0,0102 \pm 0,0035$ & $0,0121 \pm 0,0023$ & $0,0148 \pm 0,0032$ & $0,0101 \pm 0,1117$ \\
\hline Density (g.cm3) & $1,1 \pm 0,72$ & $1,1 \pm 0,05$ & $1,2 \pm 0,03$ & $1,1 \pm 0,76$ \\
\hline
\end{tabular}

Table 4. Density of the pieces manufactured by FDM.

\begin{tabular}{|c|c|c|c|c|}
\hline Measurements / Geometries & $0^{\circ}-90^{\circ}$ & $0^{\circ}-45^{\circ}-90^{\circ}$ & $0^{\circ}-45^{\circ}-90^{\circ}-135^{\circ}$ & $0^{\circ}-60^{\circ}-120^{\circ}$ \\
\hline Dry mass (g) & $0,032 \pm 0,0006$ & $0,0296 \pm 0,0004$ & $0,0323 \pm 0,0001$ & $0,0293 \pm 0,0002$ \\
\hline Wet mass (g) & $0,0101 \pm 0,0037$ & $0,0091 \pm 0,0001$ & $0,0144 \pm 0,0003$ & $0,0091 \pm 0,0016$ \\
\hline Density (g.cm3) & $1,14 \pm 0,68$ & $1,13 \pm 0,013$ & $1,14 \pm 0,02$ & $1,15 \pm 0,01$ \\
\hline
\end{tabular}

The data collected for the determination of the porosity of the FDM and SLA scaffolds are in Tables 5 and 6 , respectively.

In the tables 5 to 6 , it is possible to compare the difference obtained in the results of the porosities of the pieces manufactured by the FDM technique, as well as by the SLA technique, respectively. These results show that the parts that presented the highest porosity are those of FDM, while those of SLA obtained a porosity value even below the value of the theoretical porosity presented in Table 7. However, the bigger difference observed between theoretical and apparent porosities can be related to the difficulty of liquid penetration (ethyl alcohol) into the internal pores. 
Table 5. Porosity of the parts manufactured by FDM.

\begin{tabular}{|c|c|c|c|c|}
\hline Measurements / Geometries & $0^{\circ}-90^{\circ}$ & $0^{\circ}-45^{\circ}-90^{\circ}$ & $0^{\circ}-45^{\circ}-90^{\circ}-135^{\circ}$ & $0^{\circ}-60^{\circ}-120^{\circ}$ \\
\hline Volume of pores (cm3) & $0,1094 \pm 0,0038$ & $0,0917 \pm 0,0046$ & $0,1003 \pm 0,0162$ & $0,1185 \pm 0,0033$ \\
\hline Real volume (cm3) & $0,1352 \pm 0,0030$ & $0,1401 \pm 0,0019$ & $0,1551 \pm 0,0168$ & $0,1575 \pm 0,0035$ \\
\hline Porosity (\%) & $80,3 \pm 2,6$ & $65,1 \pm 3,3$ & $63,7 \pm 3,3$ & $75,3 \pm 1,2$ \\
\hline
\end{tabular}

Table 6. Porosity of the parts manufactured by SLA.

\begin{tabular}{|c|c|c|c|c|}
\hline Measurements / Geometries & $0^{\circ}-90^{\circ}$ & $0^{\circ}-45^{\circ}-90^{\circ}$ & $0^{\circ}-45^{\circ}-90^{\circ}-135^{\circ}$ & $0^{\circ}-60^{\circ}-120^{\circ}$ \\
\hline Volume of pores (cm3) & $0,0156 \pm 0,0224$ & $0,0145 \pm 0,0014$ & $0,0212 \pm 0,0066$ & $0,0191 \pm 0,1330$ \\
\hline Real volume (cm3) & $0,0412 \pm 0,0145$ & $0,0445 \pm 0,0112$ & $0,0539 \pm 0,0048$ & $0,0454 \pm 0,0165$ \\
\hline Porosity (\%) & $40 \pm 25$ & $32 \pm 5,4$ & $38 \pm 14$ & $44 \pm 8$ \\
\hline
\end{tabular}

Table 7. Theoretical porosity of the pieces.

\begin{tabular}{|c|c|c|c|c|}
\hline Measurements / Geometries & $0^{\circ}-90^{\circ}$ & $0^{\circ}-45^{\circ}-90^{\circ}$ & $0^{\circ}-45^{\circ}-90^{\circ}-135^{\circ}$ & $0^{\circ}-60^{\circ}-120^{\circ}$ \\
\hline Volume of pores (mm3) & 28,1 & 29,32 & 38,62 & 29,7 \\
\hline Volume of scaffolds (mm3) & 16,9 & 15,68 & 21,38 & 15,3 \\
\hline Real volume (mm3) & 45 & 45 & 60 & 45 \\
\hline Porosity (\%) & 62,44 & 65,16 & 64,37 & 66,00 \\
\hline
\end{tabular}

\section{CONCLUSIONS}

This work showed that it was possible to produce scaffolds with different geometries by both AM techniques, FDM and SLA. In spite of using different polymers for each AM process, it was observed that FDM parts presented higher porosity and higher dimensional deviation in relation to digital model than SLA parts for all geometries. The homogeneity of deposited filaments was higher for SLA scaffolds. Although, some residues from photopolymerization were observed in SLA scaffolds. The porosity obtained for scaffolds produced by both techniques is compatible with the use in Tissue Engineering, however the results showed that the parts obtained by SLA, independently of the geometry, presented dimensions with only small variations in relation to the CAD model used. Therefore, it is a more precise technique in the manufacture of scaffolds, but it demands higher budget compared to FDM.

\section{ACKNOWLEDGEMENTS}

The authors thank CETEM - Center of Mineral Technology (Rio de Janeiro, Brazil) for SEM analysis and the Brazilian agencies FAPERJ and $\mathrm{CNPq}$ for financial support.

\section{REFERENCES}

Bose S., Vahabzadeh S., Bandyopadhyay A., 2013. "Bone tissue engineering using 3D printing”, Materials Today, vol. 16,12, p.496- 504 .

Galeta T., Raos P., Stojšić J., Pakši I., 2016. "Influence of structure on mechanical properties of 3D printed objects", Procedia Engineering vol.149, p.100 - 104.

Kim D-Y., Jeon J-H., Kim J.H., Kim H-Y., Kim W-C., 2017. "Reproducibility of different arrangement of resin copings by dental microstereolithography: Evaluating the marginal discrepancy of resin copings". The Journal of Prosthetic Dentistry, vol.117 (2), p.260-266

S.M. Giannitelli, D. Accoto, M. Trombetta, A. Rainer, 2014, Current trends in the design of scaffolds for computeraided tissueengineering - Review, Acta Biomaterialia vol.10, p.580 - 594.

N. Alharbi, R. Osman, D.Wismeijer, 2016, Effects of build direction on the mechanical properties of 3D-printed complete coverage interim dental restorations, The Journal of Prosthetic Dentisty, vol.115, p.760-767.

\section{RESPONSIBILITY NOTICE}

The authors are the only responsible for the printed material included in this paper. 